\title{
Research on the Construction Effect Evaluation System of Smart CBD: A Case Study in Jiangbei New District, Nanjing, China
}

\author{
Min Hong $\mathbb{D}^{1},{ }^{1}$ Caihong Peng $\left(\mathbb{D},{ }^{2}\right.$ Mi Niu $\left(\mathbb{D},^{2}\right.$ and Zhao Xu ${ }^{1}$ \\ ${ }^{1}$ College of Hydrology and Water Resources, Hohai University, Nanjing 210098, China \\ ${ }^{2}$ Department of Civil Engineering, Southeast University, Nanjing 210098, China \\ Correspondence should be addressed to Zhao Xu; bernardos@163.com
}

Received 21 October 2020; Revised 4 January 2021; Accepted 1 February 2021; Published 13 February 2021

Academic Editor: Wen Yi

Copyright (c) 2021 Min Hong et al. This is an open access article distributed under the Creative Commons Attribution License, which permits unrestricted use, distribution, and reproduction in any medium, provided the original work is properly cited.

With the update and development of technologies such as IoT, the smart city revolution is boosting construction. Several excellent $\mathrm{CBD}$ construction projects designed in smart city construction models have emerged around the world. Exploring the construction model of the CBD through the establishment of an evaluation index system of construction effect is of great significance for CBD's future development. The main objective of this study is to analyze the factors that affect the effectiveness of the construction of the CBD by using the Delphi method and AHP and to provide a systematic method to establish an index evaluation system for the construction effect of the smart $\mathrm{CBD}$, which reflects the influencing factors of the construction effect in the CBD district from six perspectives: construction, management, service, innovation, strategy, and users. This paper also introduces the construction and development of CBD in the Jiangbei New District in Nanjing, China, and uses the indicator system established in this study to evaluate its construction effect. This paper establishes a four-level indicator system, from general to specific, and discusses the degree of impact of each indicator on the effectiveness of smart CBD construction. In order to obtain the initial evaluation data more accurately, this study classified the survey subjects into three categories, which are managers, commercial enterprise users, and ordinary residents. Finally, through the analysis of the evaluation results, the effectiveness of the construction of the Jiangbei New District CBD was evaluated, and the focus of the future smart CBD construction was pointed out. The evaluation index system for the construction effect of the smart CBD established is considered to supply a good foundation for the CBD-related study.

\section{Introduction}

As the concept of smart cities has received more and more attention, some cities have begun to flow into the construction of smart cities [1]. Cities around the world are making "smart" investments. With the further construction of smart cities, it is inseparable from the support of a series of new information technologies, such as the Internet of Things, cloud computing, and big data. Rapid urbanization is one of the characteristics of the development of many countries and is a current development trend. "Smart city" has become the theme of urban construction, and there are many different levels of exploration in various countries around the world, which have led to many branches. In order to improve the level of city management, "smart cities" have gradually become blocks, and projects in smart CBDs have become increasingly popular. The CBD is the center of the city's economic development and the core area of various commercial activities in the city, and it has a supereconomic radiation capacity. It marks the degree of modernization of a city and is a bright business card of a modern city. Whether it has a fully functional CBD has become one of the main indicators for measuring the degree of urban development. The CBD is one of the major government projects of Chinese cities in the early 21st century [2]. China has successively built a series of excellent practices such as Shanghai Hongqiao Business Area and Xiong'an New Area, as well as the Jiangbei New District in Nanjing under construction. Many western countries have also built several distinctive business area projects, such as New York, Manhattan, CBD, London City CBD, and Sidewalk Toronto [3]. 
Although the history of CBD is very short in terms of urban history, CBD can still be presented through a series of different efforts according to specific development needs. At present, with the continuous application of new technologies and new concepts to the construction, management, and operation of cities, the digital transformation of cities around the world is continuing to accelerate. As a core area where the city's economic, technological, and cultural power is highly concentrated, CBDs around the world are constantly reshaping their service models with the construction of smart cities. Actively exploring the innovative operation model of smart cities and continuing to use digital means to strengthen the entire life process of the city's planning, design, construction, and operation will be an important way to build the CBD in the future. Since the development of the smart CBD, due to inconsistent understanding of the connotation of the $\mathrm{CBD}$ and differences in urban development models and development goals in various countries, how to evaluate the construction level of the smart CBD has become an urgent topic. Therefore, the establishment of a reasonable evaluation system for smart business districts will help improve the level of construction and provide experience guidance for the construction of China's business districts in the future. As far as current research is concerned, most scholars at home and abroad focus on the construction of the CBD, such as traffic problems, emergency services $[4,5]$, and sustainability studies, or demandoriented research on the development of the CBD [6-8]. In addition, they have not systematically made a comprehensive evaluation of the construction situation nor have they established a comprehensive evaluation system for the smart construction of the CBD. Well known, through the research and evaluation of the established projects, the analysis of their advantages and disadvantages is also an idea to explore future construction plans.

With the in-depth development of economic globalization, rapid technological progress, and increasingly fierce competition worldwide, international and domestic wellknown central business districts such as the future city of Toronto, Melbourne CBD, Manchester Financial Town, and Shanghai Pudong Lujiazui are all taking effective measures to actively seize the commanding heights of technological innovation and high-tech industry development. The future city of Toronto adopts the concept of digital twin city planning and highlights the design of urban physical space with a sense of technology. The Melbourne Central Business District relies on the distributed future city laboratory to realize the real city $3 \mathrm{D}$ model to assist city management. The financial town of Manchester, UK, relies on information technology to realize automated financial supervision. Shanghai Pudong Lujiazui builds a smart community around two themes of happy community life and talent development. Breaking through the traditional park management and service model and enhancing its competitiveness and attractiveness through the construction of smart cities have become the only way for the innovation and development of the central business district. With the establishment of a series of business districts such as the Xiong'an New District and Shanghai Hongqiao, the construction of China's central business district has entered a new stage, and the planning and construction of a new model of "smart city" has become a mainstream trend. At present, a series of typical CBD projects such as Sidewalk Toronto, Sudirman CBD, Manhattan CBD, and Xiong'an New Area have been completed at home and abroad. These experiences are enough to provide research data to help establish an evaluation index system for the level of smart construction in the CBD. Therefore, combining the Delphi method and the analytic hierarchy process (AHP) to construct a smart CBD evaluation index system can improve the research on $\mathrm{CBD}$ and make up for the existing gaps. A systematic, scientific, and operable evaluation index system can help decision makers grasp the actual construction level in a timely manner to make reasonable decisions.

This paper puts forward a system of evaluation indicators for measuring smart cities from six aspects: construction, management, service, innovation, strategy, and users. At the same time, because the Jiangbei New District plays an indispensable and important role in China's "One Belt One Road," Yangtze River Economic Belt, reform and opening, and other important national development strategies and tasks, here, the CBD in the Jiangbei New District is selected as the research object, and the practicality of the evaluation system established in this paper is demonstrated by evaluating its construction effectiveness.

The rest of the paper is structured as follows: in Section 2, some important contributions of other researchers in the field of smart cities, CBD, and evaluation index system are introduced. In Section 3, a systematic method to establish an indicator system for the construction effect of the smart CBD and the general steps of this method are given. In Section 4, according to the research method, an index evaluation system for the construction effectiveness of the smart CBD is formally proposed and tested. Section 5 introduces the development of the Jiangbei New District CBD and uses the established index evaluation system to make an evaluation and analysis of it. Finally, the significance and limitations of this study are pointed out.

\section{Literature Review}

2.1. Smart City and Construction Effect. IBM is the first to formally propose the concept of "smart city" as an extension of the "smart earth," thinking that smart cities can make full use of information and communications technology (ICT) to intelligently respond to various needs in the city and create a better city life [9]. Since the concept of smart cities has been proposed, its theoretical research dynamics and practical development status have attracted much attention from academia and the industry. The concept of smart cities has continued to develop and evolve, and its definition is different among scholars and countries. There is wide agreement about the fact that smart cities are characterized by a pervasive use of ICT, which, in various urban domains, helps cities make better use of their resources. ICT is regarded as one of the main economic driving forces for the development of smart cities [10]. Harrison et al. [11], in an IBM company document, explained the basic concept of 
instrumented, interconnected, and intelligent and thought smarter cities are urban areas that use ICT to intelligently exploit operational data to optimize the operation of city services. With the development of society, the concept of smart cities is not only limited to the spread of ICT but also focuses on the needs and contact of people, communities, and nature. Hafedh et al. [12] identified eight key factors of management and organization, technology, governance, policy context, people and communities, economy, built infrastructure, and natural environment for smart cities, addressing the topic of people and communities as part of smart cities is critical. The Natural Resources Defense Council defines smarter in the urban context as more efficient, sustainable, equitable, and livable [13]. Zygiaris [14] proposed a smart city reference model based on the ecosystem, focusing on the city's environment and sustainable development. The concept of smart city is still emerging. At present, different stakeholders have different perspectives, and there is no clear and consistent definition of smart cities.

Many countries and cities have launched their smart city projects to address urbanization issues and challenges. The United States is one of the earliest countries to launch the smart city project. In 2009, the idea of IBM's smart earth [15] was publicly affirmed by U.S. President Barack Obama, and the smart earth construction plan was applied to Dubuque to achieve the complete digitalization of the city. Fietkiewicz and Stock [16] surveyed the smart levels of Tokyo, Yokohama, Osaka, and Kyoto in Japan and concluded Tokyo as the city with the highest level of smartness. Singapore launched the Smart National Plan in 2014 and launched many smart projects to build future cities. Hoe [17] conducted a case study on Singapore to explore the key characteristics of a smart country. As a developing country, China has a large volume of urban development. More than 200 smart cities have been established as pilot cities to promote the development of smart cities. There has been a global upsurge in the construction of "smart cities." Countries around the world have taken the construction of "smart cities" as a new urban development concept and practice path, and many countries have made outstanding achievements.

Currently, the construction of smart cities is based on the application of a new generation of information technology, involving multiple technical fields such as the IOT, the internet, and cloud computing. So, the function of smart cities is to focus on intelligent technology infrastructure such as the internet, the IOT, cloud computing, and big data and then acquire, analyze, integrate, and process relevant information about various elements of the city through an intelligent method. Finally, intelligent response and processing of various needs such as people's livelihood, public safety, urban services, and business activities are carried out so that the functional modules in the city are coordinated with each other. Smart cities are mainly characterized by improving the level of smart operation, promoting the development of smart industries, and ensuring efficient smart management. The goal is to achieve smart government management and services, intensification of enterprise operations, and convenience of residents' lives. With the continuous advancement of information technology and continuous improvement of urban construction, smart cities increasingly present the following basic characteristics [18-21]: (1) comprehensive and thorough perception capabilities; (2) extensive and real-time interconnection capabilities; (3) intelligent fusion decision-making capabilities; and (4) development of participatory innovation capabilities. Making full use of informatization-related technologies, integrating and optimizing existing resources through monitoring, analysis, integration, and intelligent response, to make city operations safer, more convenient, efficient, and green is the fundamental goal of smart city construction [22]. Therefore, the construction effects of smart cities are that regional governance is more coordinated and efficient; industrial development is more integrated and innovative; and public services are more intelligent and convenient.

In China, the evaluation of the effect of smart city construction is still a research focus. Qu [23] analyzed the constituent elements of smart city construction through three aspects, hardware construction, software application, and environmental conditions, to evaluate the effects of smart city construction from the five elements. These elements are smart technology infrastructure, management system construction, business investment, social risk management, and sustainable development strategy. In addition, Li et al. [24] also evaluated the effects of smart city construction from four perspectives, that is, smart infrastructure, smart economy, smart governance, and smart participation.

2.2. Construction Effect Evaluation. Since 2008, countries around the world have begun to build smart cities. Due to the inconsistent understanding of the connotation of smart cities and the differences in the development model and development goals of cities in various countries, how to evaluate the level of smart city construction has become an urgent topic. In 2007, relevant agencies were invited to set up an evaluation system for Europe's smart city construction ranking activities. The system includes six levels of smart economy, smart labor, smart government, smart travel, smart environment, and smart life. The six levels include 31 secondary indicators and 74 tertiary indicators. The indicator system sets up a clear indicator model and data processing methods, all of which are public data, which can effectively compare the overall strength of cities and reflect the key resources and comparative advantages of each city [25]. China's new smart city evaluation index system 3.0 was jointly released by the National Development and Reform Commission and the Central Cyberspace Administration of China in 2016. It is China's first national-level indicator system established and officially put into use. The indicator system is formulated on the principle of "people-oriented, beneficial to the people, performance-oriented, and objective quantification." And it is divided into three parts: objective indicators, subjective indicators, and optional indicators. It contains 8 first-level indicators, 21 second-level indicators, and 54 third-level indicators, namely, services for the people, precise governance, ecological livability, smart 
facilities, information resources, network security, reform and innovation, and citizen experience. Among them, 3 performance indicators (benefiting the people, precise governance, and ecological livability) and 4 guiding indicators (smart facilities, information resources, network security, and reform and innovation) are objective indicators, aimed at the evaluation of the development status, development space, and development characteristics of the city. Subjective indicators refer to the experience of citizens, and to guide the evaluation of cities, attention should be paid to the participation of the masses in urban construction and public satisfaction. The self-selected indicators are determined by each city in accordance with local characteristics and objective indicators when conducting smart city evaluation. The new smart city indicator system 3.0 is an indicator system that attaches great importance to "benefiting the people." The sum of the weights of the two indicators, benefiting the people service and citizen experience, accounts for $57 \%$, which has guided the focus of China's smart city construction to a certain extent.

At present, most of the indicators used in the evaluation index system of smart cities are more general indicators to measure the level of urban informatization and economic development. The combination with smart cities is low and does not fully reflect the connotation of smart cities. As a nongovernmental evaluation system, the EU's indicator system aims to make a unified evaluation of multiple cities, while ignoring their respective characteristics. Building a smart city is a long-term and huge project, and input-output and performance evaluation are both essential parts. The existing indicator system generally attaches great importance to the measurement of input and output, especially the domestic indicator system, such as wireless network construction, fixed asset investment, and R\&D expenditures, but lacks the evaluation of the benefits after input. Therefore, in the process of formulating a smart city evaluation index system, it should be benefit-oriented and balance inputoutput and benefit indicators in order to measure the effect of urban smart construction.

In the process of index selection, Ma et al. [26] established a comprehensive evaluation index framework on the conceptual model by consulting relevant literature. The selection of general evaluation indicators is derived from the existing relevant literature, but the establishment of some research indicator systems does not stop there. Based on the initial indicators, the evaluation system established by using the Delphi method to repeatedly screen the evaluation indicators is more scientific and credible [27]. Based on the Delphi method and AHP, Cheng et al. [27] built a complete low-carbon tourist attraction evaluation system and conducted empirical research with Xixi Wetland. Studies have shown that this evaluation system is also applicable to evaluation research in other fields when the Delphi method is not difficult to operate. Feng [28] pointed out a set of key indicators of intelligent city construction through the scientific method to construct a multilevel evaluation index system which conforms to China's national conditions. Through expert investigation and analytic hierarchy process (AHP), he determined the weight of each index and finally completed the scientific and reasonable wisdom urban construction evaluation index system for the establishment of China's wisdom for the city to provide a reference. Ko et al. [29] used Delphi techniques to analyze the future evaluation indexes and policy directions of Jeju Special SelfGoverning Province in creating a smart traffic safety city and came to the conclusion that the important factors in the urban environment and welfare components were the enhancement of individual health and well-being, environmental protection and pollution prevention, living and quality of life, waste management services, low-carbon green energy use, smart grid infrastructure, U-Hospital services, and ongoing education programs.

Numerous studies have shown that, for comprehensive evaluation methods, the most popular is still to establish an index evaluation system based on the Delphi method and the AHP. The combination of the Delphi method and the AHP makes the evaluation system and calculation results more scientific, effective, and reliable. Such evaluation system construction methods have been applied in many fields.

2.3. $C B D$. $\mathrm{CBD}$ (central business district) was originally proposed by E. W. Burgess, American urban geographer. As an important function-bearing area of the city, CBD has certain uniqueness in its system structure and development mode. Some scholars pointed out in their research on Songdo IBD (international business district): Songdo IBD is not only a high-tech business district but also an ideal template for future urban construction activities. It has an intelligent infrastructure and self-regulating system, showing the "luxury atmosphere everywhere," where everyone is wealthy, and all processes from paying bills to controlling the temperature of the apartment are computerized [30-33]. Comprehensive research shows that the characteristics of the $\mathrm{CBD}$ are mainly manifested in the following aspects. First, its business activities, office facilities and services, and entertainment facilities are dense and highly complex and have strong radiation capabilities. Second, within the scope of the $\mathrm{CBD}$, the tertiary industry plays a leading role and gradually replaces the manufacturing industry. Some CBDs have the most concentrated and highest level of retail in the region. Third, CBD usually has peak land value. The intensity of land development and utilization is relatively high. Generally, it has the highest land price and rent in the city. Fourth, the area ratio of the $\mathrm{CBD}$ and the density of buildings are high, and the form of buildings grows vertically. Fifth, CBD is the most visited area in the urban area and the most populated area in the urban area. Sixth, it has high employment density and high-quality employees. Finally, it is a busy high traffic center. It has more accessibility [34].

In the process of development and construction, due to complex factors and decomposition, tradeoffs, comprehensive transformation, convergence and mutual relations, and other factors, as well as the environment and stakeholders, the builders often do not fully develop effective information. For a large CBD construction project portfolio, it is particularly important to accurately analyze project task requirements and convert user needs into product 
characteristics [6-8]. Based on the development example of the CBD construction project portfolio, Zhang [8] introduced the entropy method into the traditional model of quality function deployment (QFD) to deal with data ambiguity caused by incomplete information. In this study, first, determine the weight of user demand indicators, analyze the relationship between various indicators through QFD, and then convert the demand characteristics into technical characteristics. Second, determine the weight and relevance of technical features, and convert user needs into product features more comprehensively, objectively, and realistically.

The CBD is a comprehensive smart block, which has the characteristics of high compound, digitization, humanization, and ecology. According to the smart city evaluation system, the evaluation of the CBD should also consider its characteristic service quality. Vanolo [35] claimed that similar city-building projects framed as "smart," ecofriendly, and sustainable are already in the advanced state of planning. Sustainability has been widely accepted as an important conceptual framework, and people can consider the case of using sustainability principles to support CBD projects [36]. A multiple-case study was conducted in Finland to examine how CBD developments are designed to facilitate environmental sustainability. By simulating the development process of the Finnish CBD, the results of the sustainability analysis are provided [37]. Safety is also one of the assessment elements of the CBD [4, 5]. As Anyumba [4] pointed out, in a 'worst case scenario,' the emergency services would face formidable infrastructure, human, and mobility obstacles in their pathways. The study findings point to the importance of emergency security in the construction of Thohoyandou CBD. Therefore, the operating mechanism of the emergency service system needs to be examined to reduce the potential risk of man-made disasters in the CBD.

At present, with the continuous application of new technologies and new concepts to the construction, management, and operation of cities, the digital transformation of cities around the world is continuing to accelerate. As a core area where the city's economic, technological, and cultural forces are highly concentrated, CBDs around the world are constantly reshaping their service models with the construction of smart cities. They actively explore innovative operation models for smart cities and continue to use digital means to strengthen the entire life process of the city's planning, design, construction, and operation. The digital transformation of the CBD is represented by the "smart city," a new data-centric urban development model.

The construction of the CBD is still in its infancy and exploration stage, especially in China. Current research on the CBD focuses on specific needs, such as sustainability and emergency service systems. These studies are mainly discussing the construction plan of the smart CBD, aiming to provide effective suggestions and guidance for the construction of the CBD in the future. Therefore, most scholars are not involved in the research on the late evaluation of CBD construction. With the completion of the construction of a batch of excellent CBDs, the evaluation of their construction effectiveness can not only find the shortcomings in the construction process but also provide effective suggestions and references for future CBD construction.

\section{Research Methodology}

The main objective of this study is to analyze the factors that affect the effectiveness of the construction of the CBD by using the Delphi method and AHP and to provide a systematic method to establish an index evaluation system for the construction effect of the smart CBD. And then, it evaluates the construction effect of the CBD in the Nanjing Jiangbei New District. Figure 1 shows the general steps involved in this proposed method. The procedure starts with analyzing the importance and relevance of impact factors and establishes an index evaluation system with six dimensions through the Delphi method, AHP, multicriteria analysis, and evaluation indicators. These six dimensions are construction, management, service, innovation, strategy, and citizen experience. Through the establishment of the evaluation system, the CBD classification system was formulated. During the establishment of the system, this study chose to combine the Delphi method and AHP. First, the Delphi method is used to obtain expert suggestions, and then the AHP checks the rationality of the indicators, and to obtain relatively representative evaluation indicators. For computation, here, this paper establishes a four-level indicator system, from general to specific, and discusses the degree of impact of each indicator on the effectiveness of smart $\mathrm{CBD}$ construction. At the next stage, in the evaluation of the construction effectiveness of the Jiangbei New District $\mathrm{CBD}$, in order to obtain the initial evaluation data more accurately, this study classified the survey subjects into three categories according to the index classification, which are the managers, the commercial enterprise users, and the ordinary residents. This can ensure the validity of the evaluation results. Finally, through the analysis of the evaluation results, the effectiveness of the construction of the Jiangbei New District CBD was evaluated, and the focus of the future smart CBD construction was pointed out. The methodology used in each of the above stages is presented in the following sections.

\section{The Design of the Construction Effect Evaluation Indicator System for the Smart CBD}

According to evaluation indicators for new-type smart cities [38] in China, the evaluation of smart city construction considers 8 factors: services for the people, precise management, ecological livability, smart facilities, information resources, network security, reform and innovation, and citizen experience. Sun and $\mathrm{Li}$ [39] built a smart city information security evaluation index system from four aspects, management, technology, strategy, and users, based on the information security evaluation indicators established at home and abroad and the characteristics of smart cities. Ningbo Smart City Planning Standards Development Research Institute and Zhejiang University and other 


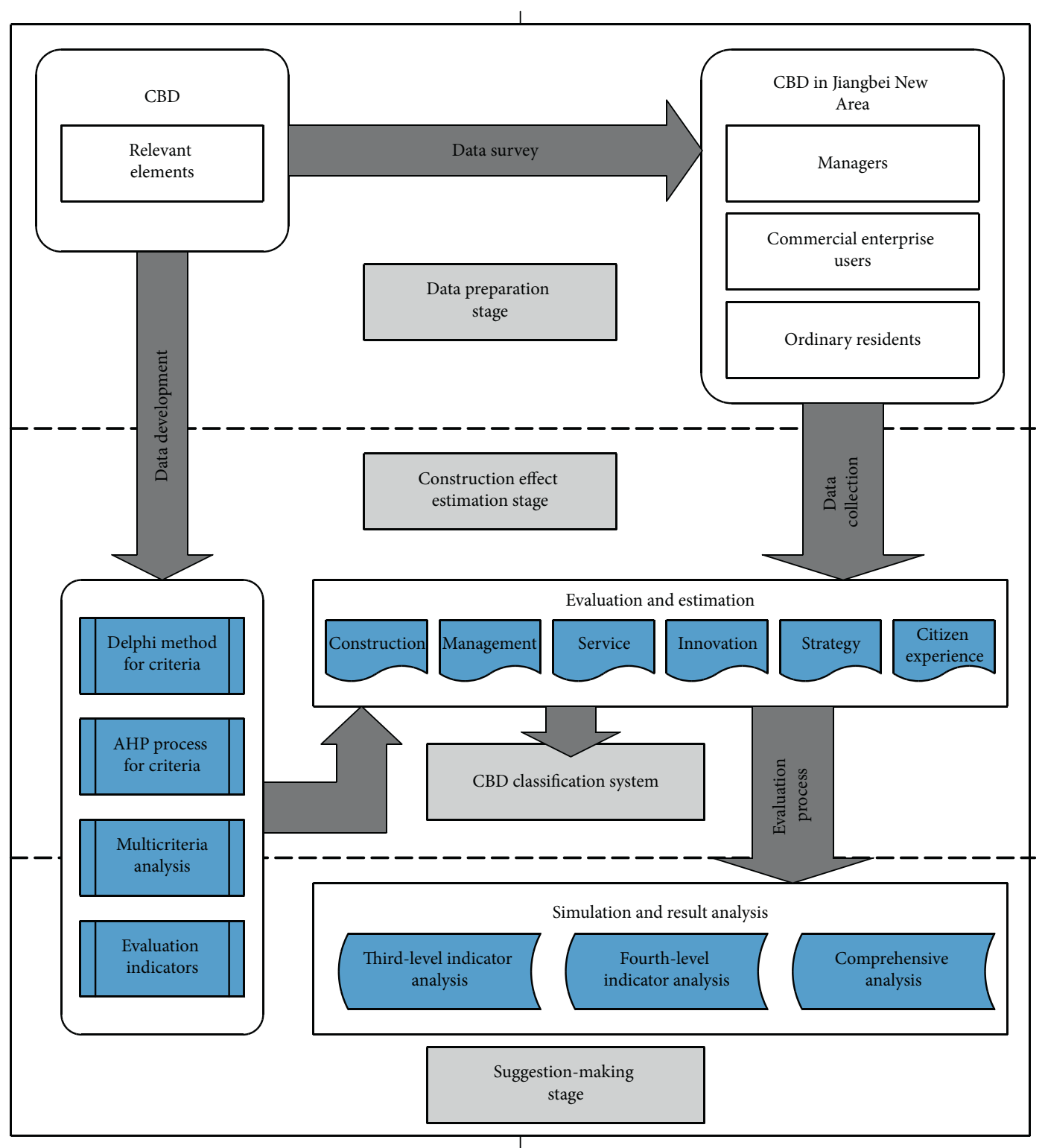

Figure 1: The procedure of the construction effect evaluation of the smart CBD.

institutions of higher learning have jointly determined the Ningbo smart city evaluation index system. The indicator system is divided into 7 first-level indicators, 21 second-level indicators, and 48 third-level indicators for smart people, smart infrastructure, smart governance, smart people's livelihood, smart economy, smart environment, and smart planning and construction. The "smart Nanjing" indicator system was constructed by the Nanjing Information Center in 2010. The indicator system includes evaluation systems in four areas: urban infrastructure, urban smart industry, urban smart services, and urban smart humanities, including a total of 23 evaluation indicators. Although the indicator system has not been put into use, it is an early exploration of smart city evaluation and will also have important reference significance for the construction of the indicator system of the $\mathrm{CBD}$ in the future.
After screening the indicators that are frequently discussed and evaluated in the standards [40] and related literature studies $[25,36,41]$, the original 58 evaluation indicators are selected in consideration of the suitability and reliability of the indicator in construction effect evaluation, which are summarized in Table 1.

4.1. Construction Effect Evaluation Indicator System. Based on the 58 indexes, an advisory group of experts was composed that included 5 experts from the construction industry, 20 graduates of engineering management and urban planning, and 5 technical staff of information technology company. Each of the 30 experts received a copy of the questionnaire. The experts were requested to provide his or her advice and recommendations regarding the indexes. 
TABLE 1: The original evaluation indexes for the smart CBD.

\begin{tabular}{|c|c|}
\hline No. & Index content \\
\hline 1 & Forward-looking \\
\hline 2 & Execution intensity \\
\hline 3 & Innovative \\
\hline 4 & Broadband network penetration \\
\hline 5 & Wireless network penetration \\
\hline 6 & Perceived device coverage \\
\hline 7 & Internet of Things access rate \\
\hline 8 & Network, computing, storage resource virtualization service provision \\
\hline 9 & Multimedia classroom penetration \\
\hline 10 & Network learning space coverage \\
\hline 11 & School wireless network coverage \\
\hline 12 & Popularization rate of electronic medical records in medical institutions \\
\hline 13 & Appointment rate of medical institutions \\
\hline 14 & Review rate of outpatient health files in medical institutions \\
\hline 15 & One-stop processing rate \\
\hline 16 & Unified certification \\
\hline 17 & The number and use of registered enterprises on the financial service platform \\
\hline 18 & Financial experience center exhibition, event usage \\
\hline 19 & Real-time update speed of traffic situation \\
\hline 20 & Traffic information forecast rate \\
\hline 21 & Ride electronic payment rate \\
\hline 22 & Traffic positioning accuracy \\
\hline 23 & Public safety video resource collection and coverage \\
\hline 24 & Public security video surveillance resource networking and sharing degree \\
\hline 25 & Early-warning efficiency of public safety \\
\hline 26 & Critical information infrastructure supervision \\
\hline 27 & Data leakage prevention, backup, encryption \\
\hline 28 & Security defense capability \\
\hline 29 & Risk-handling efficiency \\
\hline 30 & Online monitoring of key pollution sources \\
\hline 31 & Environmental information disclosure rate of enterprises and institutions \\
\hline 32 & Business district environmental problem resolution rate \\
\hline 33 & Green building coverage \\
\hline 34 & Online monitoring rate of key energy-using units \\
\hline 35 & Energy consumption reduction rate per 10,000 yuan of GDP \\
\hline 36 & Artificial intelligence \\
\hline 37 & BIM application level \\
\hline 38 & Big data technology \\
\hline 39 & Edge computing \\
\hline 40 & Blockchain technology \\
\hline 41 & Rationality of investment and financing model \\
\hline 42 & Construction model \\
\hline 43 & Management mechanism \\
\hline 44 & Return on investment \\
\hline 45 & Virtualization \\
\hline 46 & Storage capacity \\
\hline 47 & Calculate ability \\
\hline 48 & Visualization \\
\hline 49 & Openness rate of public information resources \\
\hline 50 & Sharing rate among information resource departments \\
\hline 51 & Development of basic information resources by government-enterprise cooperation \\
\hline 52 & Information symmetry \\
\hline 53 & Timeliness of data \\
\hline 54 & Card usage \\
\hline 55 & Smart service platform utilization rate \\
\hline 56 & Satisfaction with business function coverage \\
\hline 57 & Online and offline process progress synchronization \\
\hline 58 & Site supervision coverage \\
\hline
\end{tabular}

Reference source: evaluation indicators for new-type smart cities of China. 
Of the 30 questionnaires distributed for review, 25 copies were returned. In the 25 responses, the selection rate for the indexes was $60 \%$. There were 39 indexes that were selected $\geq 15$ times, whereas 19 indexes had a selection rate of less than $\leq 60 \%$. As the latter indexes are not viewed as being highly correlated with the subject under discussion, they were omitted from the study.

These indexes were identified and evaluated in two rounds of expert questionnaire surveys. The indexes were modified and adjusted based on the experts' feedback after the first questionnaire survey. To signify that an index was "very important," "relatively important," "general," "unimportant," or "not important at all," the experts assigned a score of $9,7,5,3$, or 1 , respectively. Then, the statistical results were returned to the experts, who again evaluated the indexes. This process made it possible to identify the evaluation indexes for the smart CBD.

The arithmetic mean of all the above values for an index indicates the experts' "degree of opinion concentration"; the higher the arithmetic mean, the greater the importance of the index. The coefficient of variation for each index is similarly used to indicate the experts' "degree of opinion coordination"; the smaller the coefficient of variation of the index, the lesser the dispute regarding the index.

Based on the results of two rounds of index selection and the analysis of these findings, 29 evaluation indexes for the smart CBD were selected, as indicated in Table 2.

By consulting experts, an evaluation index system for the smart CBD is developed. This system evaluates the construction, the management, the service, the innovation, the strategy, and the citizen's attitude. These six second-level indexes are divided into third-level indexes and fourth-level indexes. The weight of each index is determined using the AHP and the third round of questionnaires, which were given to 30 experts. The experts were asked to judge the degree of importance of each index and to grade each index using hierarchical pairwise comparisons. The weight of each index was thus determined.

In AHP, to quantify policy-making judgments, a judgment matrix must be constructed using the 1-9 scale method according to the hierarchy and the quantity of the indexes, as shown in Table 3. The overall judgment of the weights of multiple elements of the smart CBD is transformed into a "pairwise comparison" of these elements, and the comparison results are converted into quantitative judgment data to form a judgment matrix. For each judgment matrix, the degree of relative importance can be scaled separately.

Data were input into AHP software to construct the model for obtaining the weight of each element in the matrix and for determining whether the matrix is consistent. It was determined that all matrices are consistent. Calculate its maximum eigenvalue and eigenvector through the judgment matrix. The method used in this paper is the square root method. Set the judgment matrix $B=\left(b_{i j}\right) m \times m$ (as shown in Table 4$)$. The specific steps are as follows:

(1) Calculate the product of each row of the judgment matrix:

$$
N_{i}=\sum_{j=1}^{m} B_{i j}
$$

$i=1,2,3, \ldots, m$.

(2) Calculate the $m$-th root of $N_{i}$ :

$$
\overline{w_{i}}=\sqrt[m]{N_{i}}
$$

$i=1,2,3, \ldots, m$.

(3) Normalize the vector $\overline{w_{i}}, \overline{w_{i}}=\left(\overline{w_{1}}, \overline{w_{2}}, \ldots, \overline{w_{m}}\right)^{T}$ :

$$
w_{i}=\frac{\overline{w_{i}}}{\sum_{i=1}^{m} w_{i}}
$$

$i=1,2,3, \ldots, m$.

(4) Calculate the largest characteristic root of the judgment matrix:

$$
\lambda_{\max }=\frac{1}{m} \sum_{i=1}^{m} \frac{\left(B_{w}\right)_{i}}{w_{i}},
$$

and $\left(B_{w}\right)_{j}$ is the $i$-th component of $B_{w}$.

(5) Consistency test of the judgment matrix.

The corresponding consistency ratio of each $m$-order matrix: $\mathrm{CR}=\mathrm{CI} / \mathrm{RI}, \mathrm{CR}=\left(\lambda_{\max }-m / m-1\right)$, and $\mathrm{RI}$ is the average random consistency index, as shown in Table 5. If $\mathrm{CR}<0.1$, the consistency of the judgment matrix meets the requirements, that is, the judgment result is reliable; otherwise, the judgment matrix needs to be reconstructed.

4.2. Evaluation Indicator Weights. Of the 30 copies of the questionnaire that were distributed, 25 were returned (for a response rate of $83 \%)$. The weight $(38.8 \%)$ of the "construction" index and "service" (27.4\%) is far greater than that of the "management" (14.5\%), "innovation" (8\%), "strategy" (3.2\%), and "citizen experience" (8.1\%) indexes. This indicates that construction factors and service effect are the most important in the evaluation of the smart CBD. The four third-level factors in this category are critical including "the smart project, smart facilities, precision governance, and industry service." Of the 29 specific indexes, the total weight of the digital city management (7\%), the city management and intelligent analysis (6\%), the new financial industry services (8.5), and citizen satisfaction $(8.1 \%)$ had the maximum values. Thus, these four indexes should also be given high priority in the process of developing smart CBD.

First, to indicate the level of smart construction associated with each index, the indexes were divided into five levels: A, B, C, D, and E. The values associated with the respective levels were as follows: $(80,100],(60,80],(40,60]$, $(20,40]$, and $(0,20]$, respectively. When applying the index evaluation system, in order to better reflect the actual construction level from the perspective of being served, when evaluating the smart construction level of a specific CBD, this study selects citizens in the area to evaluate and 
TABLE 2: Construction effect evaluation indicators for the smart CBD.

Indicator

Construction L1

$(38.8 \%)$
Building L111 (2.6\%)

Smart project L11

(12.9\%)

Ecological landscape L112

$(2.6 \%)$

Municipal administration L113 (2.6\%)

Pipeline L114 (2.6\%)

Traffic L115 (2.5\%)

Broadband network L121 (5\%)

Smart facilities L12

$(11.3 \%)$

Information resource L13 (8.1\%)

Internet of Things L122 (3\%)

Cloud infrastructure L123

(3.3\%)

Open sharing L131 (5.1\%)

Development and utilization L132 (3\%)

Network security mechanism Network security L14 L141 (3\%) $(6.5 \%)$

System and data security L142 $(3.5 \%)$

Digital city management L211 (7\%)

City management and

Management L2 Precision governance intelligent analysis L212 (6\%)

$(14.5 \%)$ L21 (14.5\%)
Explanation

(i) IoT coverage rate of key management units of buildings

(ii) The coverage rate of the deployment of basic intelligent building systems

(iii) The construction and use of smart building platforms

(i) The deployment of ecological grid IoT facilities

(ii) The construction and application of ecological grid monitoring management platform

(i) Coverage rate of digital signage for municipal components

(ii) Intelligent construction of municipal components

(iii) Construction and use of municipal management platform

(i) Coverage rate of comprehensive pipe gallery

(ii) Intelligent construction of pipeline facilities of pipe gallery

(iii) Intelligent monitoring operation and maintenance of municipal pipeline gallery pipelines

(i) Intelligent regulation of dynamic and static traffic

(i) Penetration rate of fixed broadband buildings

(ii) FTTH user penetration rate

(iii) Penetration rate of mobile broadband users

(i) Indoor and outdoor IoT network coverage

(ii) Access rate of IoT devices

(i) Network, computing, and storage resource virtualization service provision

(i) The open rate of public information resources(ii) Sharing rate among information resource departments

(i) The development of basic information resources by government-enterprise cooperation

(i) Smart city network security organization and coordination mechanism

(ii) Notification agencies and mechanisms to share information and report early warning to improve prevention and control capabilities

(iii) Establish and improve network security emergency response mechanisms to improve risk response capabilities (i) Implement effective security protection for critical information infrastructure

(ii) The supervision of critical information infrastructure

(i) CIM system function

(i) Operation center perception, display, and collaborative command services

(ii) Operation center intelligent analysis service

(i) Public safety video resource collection and coverage

(ii) Networking and sharing degree of public security video

Public safety L213 (1.5\%) surveillance resources

(iii) Public safety video images enhance social management capabilities 
TABle 2: Continued.

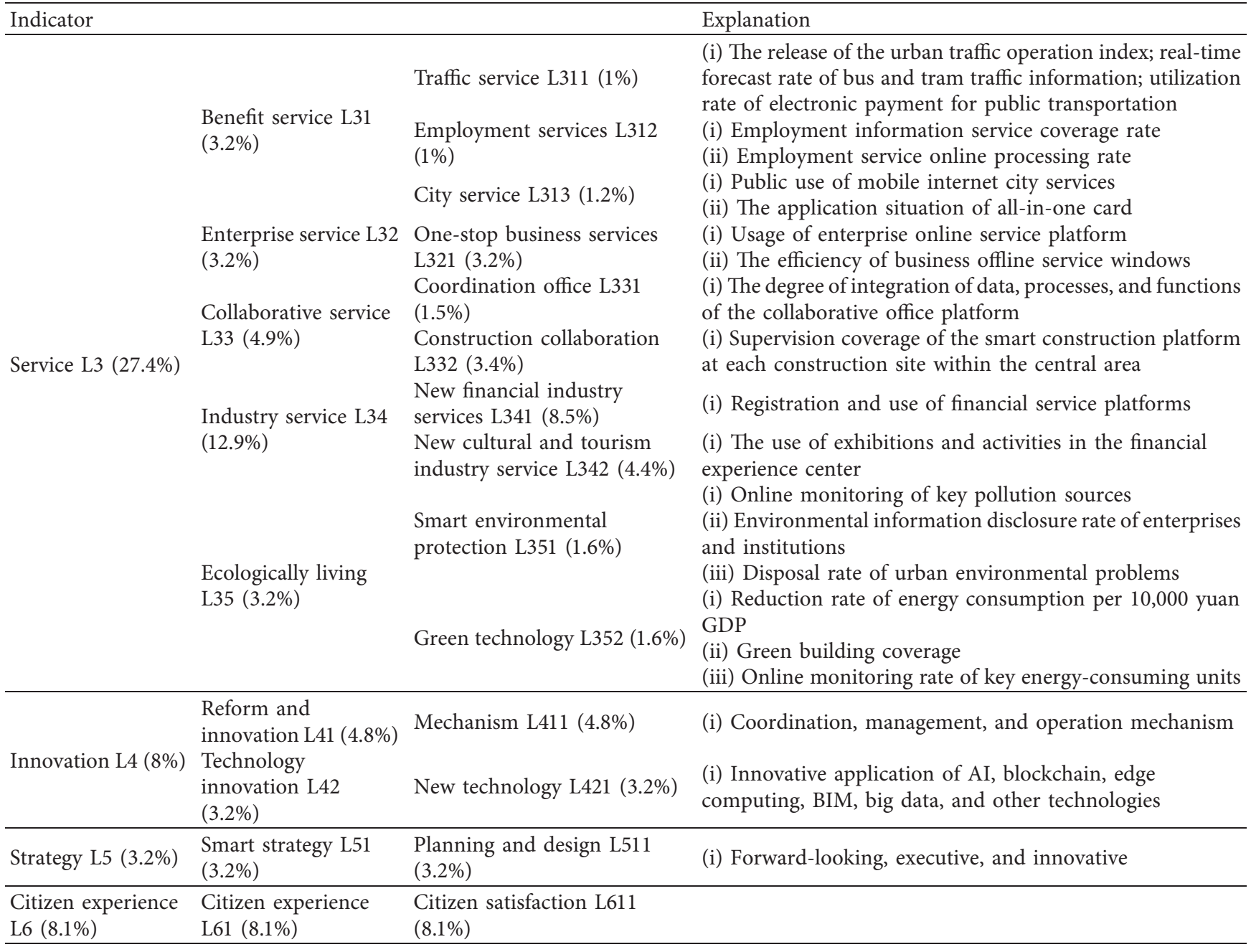

TABLE 3: 1-9 scaling method.

\begin{tabular}{|c|c|c|}
\hline $\begin{array}{l}\text { Paired comparison } \\
\text { criteria }\end{array}$ & Definition & Content \\
\hline 1 & Equally important & Compared with two elements, they have the same importance \\
\hline 3 & Slightly important & Compared with two elements, one element is slightly more important than the other \\
\hline 5 & Quite important & $\begin{array}{c}\text { Compared with two elements, one element is significantly more important than the } \\
\text { other }\end{array}$ \\
\hline 7 & Obviously important & Compared with two elements, one element is more important than the other \\
\hline 9 & $\begin{array}{l}\text { Absolutely } \\
\text { important }\end{array}$ & Compared with two elements, one element is extremely important than the other \\
\hline $2,4,6,8$ & & The median value of the above adjacent judgment \\
\hline
\end{tabular}

TABLE 4: Judgment matrix.

\begin{tabular}{|c|c|c|c|c|c|c|}
\hline$A_{k}$ & $B_{1}$ & $B_{2}$ & $\ldots$ & $B_{i}$ & $\ldots$ & $B_{m}$ \\
\hline$B_{1}$ & $B_{11}$ & $B_{12}$ & $\ldots$ & $B_{1 i}$ & $\ldots$ & $B_{1 m}$ \\
\hline$B_{2}$ & $B_{21}$ & $B_{22}$ & $\ldots$ & $B_{2 i}$ & $\ldots$ & $B_{2 m}$ \\
\hline$\cdots$ & $\cdots$ & $\ldots$ & $\ldots$ & $\cdots$ & $\ldots$ & $\cdots$ \\
\hline$B_{i}$ & $B_{i 1}$ & $B_{i 2}$ & $\ldots$ & $B_{4 i}$ & $\ldots$ & $B_{i m}$ \\
\hline$\ldots$ & $\ldots$ & $\ldots$ & $\ldots$ & $B_{5 i}$ & $\ldots$ & $\ldots$ \\
\hline$B_{m}$ & $B_{m 1}$ & $B_{m 2}$ & $\ldots$ & $B_{6 i}$ & $\ldots$ & $B_{m m}$ \\
\hline
\end{tabular}


TABLE 5: RI value reference.

\begin{tabular}{lcccccccccc}
\hline Order & 3 & 4 & 5 & 6 & 7 & 8 & 9 & 10 & 11 & 12 \\
\hline RI & 0.52 & 0.89 & 1.12 & 1.26 & 1.36 & 1.41 & 1.46 & 1.49 & 1.52 & 1.54 \\
\hline
\end{tabular}

score each indicator. The evaluation will be based on the questionnaire star website issuing survey questionnaires to citizens in the $\mathrm{CBD}$, and then collect and count the score data obtained. The final score for the index was as follows:

$$
\text { index score }=\sum \frac{\text { citizen value }}{\text { the number of citizens }} \text {. }
$$

Suppose that the smart construction score of a CBD is $Q$; given $W_{i}$ (the index weight determined) and $K_{i}$ (the score for each index). To give due attention to the fairness of the CBD's score, many citizens scored the smart construction level of the CBD, and the final score for each CBD was the arithmetic mean of the citizen scores.

$$
Q=\sum_{i=1}^{29} W_{i} k_{i}
$$

For each index used in this research, the smart construction effect of the CBD is obtained. According to the values obtained, CBDs can be divided into five levels: firstlevel smart CBDs, second-level smart CBDs, third-level smart CBDs, fourth-level smart CBDs, and fifth-level smart CBDs, as shown in Table 6.

\section{Evaluation of the Smart CBD in Jiangbei New District, Nanjing}

With the in-depth development of economic globalization, rapid technological progress, and increasingly fierce competition worldwide, international and domestic well-known CBDs such as the future city of Toronto, Melbourne CBD, Manchester Financial Town, and Shanghai Pudong Lujiazui are all taking effective measures to actively seize the commanding heights of technological innovation and high-tech industry development. With the rapid development of China's economic development and urban construction, cities have successively begun planning and constructing CBDs. The CBD is an urban functional area with a certain particularity, and it is also an indispensable humanized living space for urban residents. The Jiangbei New District in Nanjing is located at the strategic intersection of the three major national strategies of "One Belt One Road," the Yangtze River Economic Belt, and the regional integration of the Yangtze River Delta. Only five years after it was approved, the new district's gross product value increased by 130 billion yuan, and the population increased by more than 800,000 . Its economic growth rate has led the province and the entire city for 9 consecutive quarters, and the role of regional growth poles has become increasingly prominent. In China, the Jiangbei New District is a national-level comprehensive functional area that undertakes important national development strategies and tasks such as the "Belt and Road," the Yangtze River Economic Belt, and reform and opening. The CBD in the Jiangbei New District uses a new generation of information technology as a means and focuses on encouraging innovation and services to develop smart city construction. Therefore, choosing the CBD in the Jiangbei New District as the research object will have reference value for China's current and future CBD construction.

\subsection{Development of CBD in the Jiangbei New District}

5.1.1. Location. The Jiangbei New District, a national new district in China, is located to the north of the Yangtze River in Nanjing city, the capital of Jiangsu province. As shown in Figure 2, it consists of Pukou District, Liuhe District, and Qixia District, Baguazhou Street, with a total area of 2,451 square kilometers, accounting for $37 \%$ of Nanjing's urban area. The Jiangbei New District was approved by the State Council of China on June 27, 2015. It is the 13th in China and the only state-level new district in Jiangsu province. The CBD of the Jiangbei New District is from Pubin Road in the north, Weisan Road-crossing tunnel in the east, Binjiang coastline in the south, and Qili River in the west. It is located on the side of the Yangtze River, with the Qili River in between, occupying the traffic arteries between the Nanjing Yangtze River Tunnel and Didi Line 10, as if it has choked the north and south throats of the Yangtze River. Relying on its geographical advantages and convenient transportation conditions, the CBD will provide strong support for the "One Belt One Road" strategy, lead the development of the Yangtze River Economic Belt and the Yangtze River Delta, and become a pioneer in Nanjing's construction of a globally influential and innovative city.

5.1.2. Goal of Construction. The smart construction of the CBD in the Jiangbei New District will closely follow the core positioning of "one center" in the "two cities and one center," It takes "overall planning, high-level sharing, integrated services, and smart decision-making" as its core features, and its overall vision is to build a "heart of service, integration, wisdom, and leadership." In this way, it will realize the integrated development of the industry, city, and people in the central business region, a high concentration of innovative elements, convenient and inclusive public services, and intelligent and efficient city management and help the CBD become a new financial center of Yangtze River that radiates the Yangtze River Economic Belt and has international influence.

5.1.3. Architecture Analysis. The CBD is the core area of the Jiangbei New District and a national-level comprehensive functional area that undertakes important national development strategies such as the "Belt and Road," the Yangtze River Economic Belt, and "reform and opening up." So, it integrates multiple smart functions, such as new finance, business and commerce, cultural leisure, and ecological livability. With the help of smart city construction, it will lead the development of the Jiangbei New District. The smart construction of the CBD of the Jiangbei New District 
TABLE 6: CBD classification system.

\begin{tabular}{lccccc}
\hline Level & First level & Second level & Third level & Fourth level & Fifth level \\
\hline $\begin{array}{l}\text { Value } \\
\text { range }\end{array}$ & $(90,100]$ & $(80,90]$ & $(70,80]$ & {$[60,70]$} & $(0,60)$ \\
Evaluation & $\begin{array}{c}\text { The smart construction is } \\
\text { excellent and needs to be } \\
\text { maintained }\end{array}$ & $\begin{array}{c}\text { The smart } \\
\text { construction is } \\
\text { relatively good }\end{array}$ & $\begin{array}{c}\text { The smart } \\
\text { construction is ok, } \\
\text { barely qualified }\end{array}$ & $\begin{array}{c}\text { The smart construction is } \\
\text { insufficient and needs to } \\
\text { be enhanced }\end{array}$ & $\begin{array}{c}\text { The smart construction } \\
\text { is poor and must be } \\
\text { improved }\end{array}$ \\
\hline
\end{tabular}
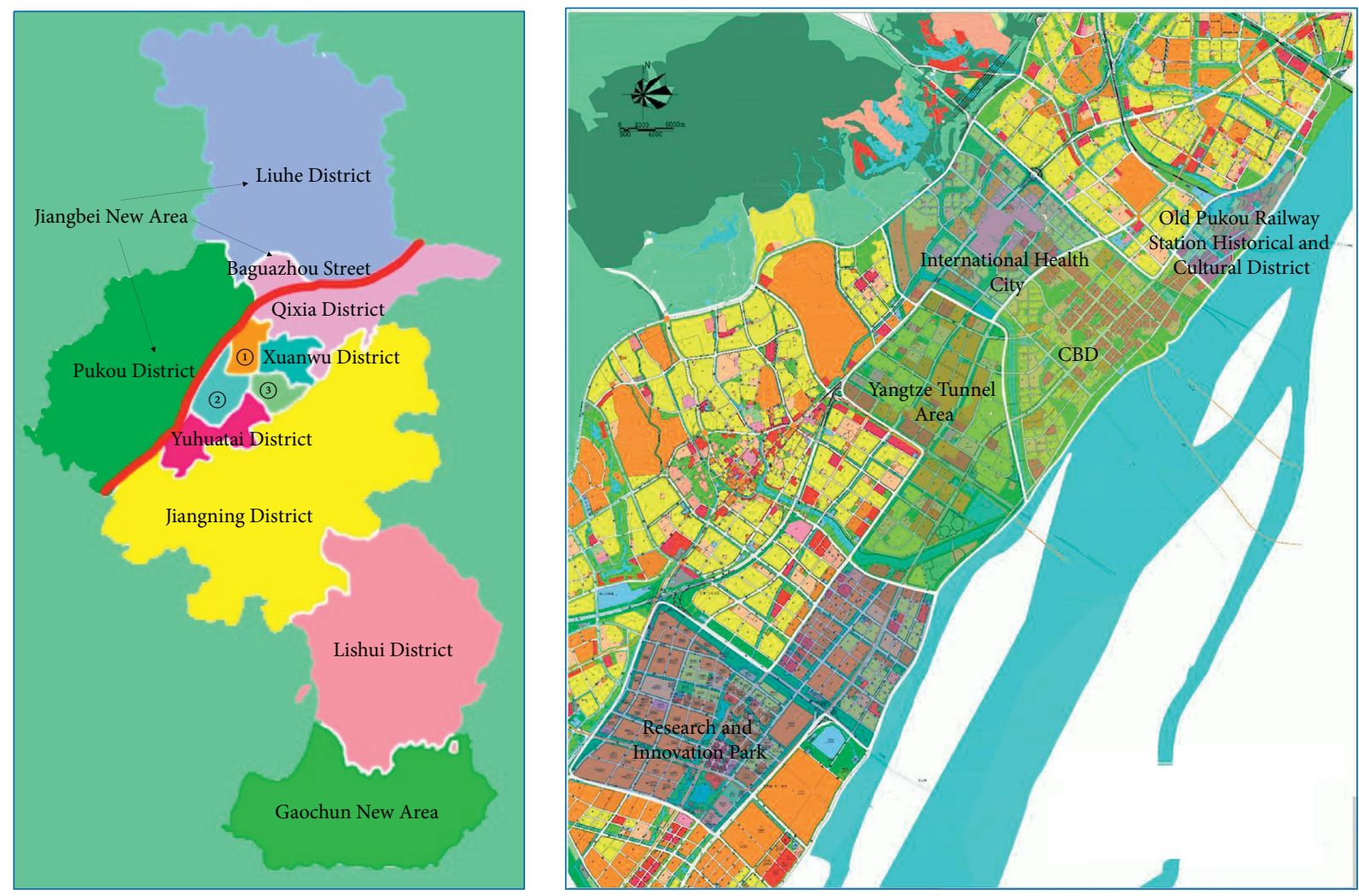

(1) Gulou District

(2) Jianye District

(3) Qinhuai District

Figure 2: Location map of Jiangbei New District, Nanjing, China.

will use new technologies such as the Internet of Things, edge computing, big data, BIM, artificial intelligence, and blockchain to create a real-time, dynamic, and interactive digital twin between humans, machines, and things. It uses the digital twin space to intelligently support and expand the dynamic and sustainable development of the physical world.

The skeleton mainly includes three layers: physical perception layer, platform support layer, and smart system layer (as shown in Figure 3).

(1) The First Layer (Physical Perception Layer). Through the deployment of IoT sensors on the sky, ground, underground, and other spatial levels of the CBD, to create a comprehensive perception physical space including municipal awareness, traffic awareness, ecological awareness, architectural awareness, and security awareness. Combined with technologies such as BIM, GIS, and IOT, a unified digital identification of various urban components and objects in the CBD is realized, and a comprehensive digital modeling of roads, bridges, manhole covers, lamp covers, buildings, and other infrastructure in the CBD is realized.

(2) The Second Layer (Platform Support Layer). To create a converged network, including a high-speed, flexible, and intelligent broadband network, and a fully covered and widely touched Internet of Things, that is, to promote deep coverage of optical fiber broadband networks and threedimensional full coverage of wireless networks (Wi-Fi, 4G/ $5 \mathrm{G}$ ) to create an Internet of Things network covering indoor and outdoor and underground environments in the CBD. In 


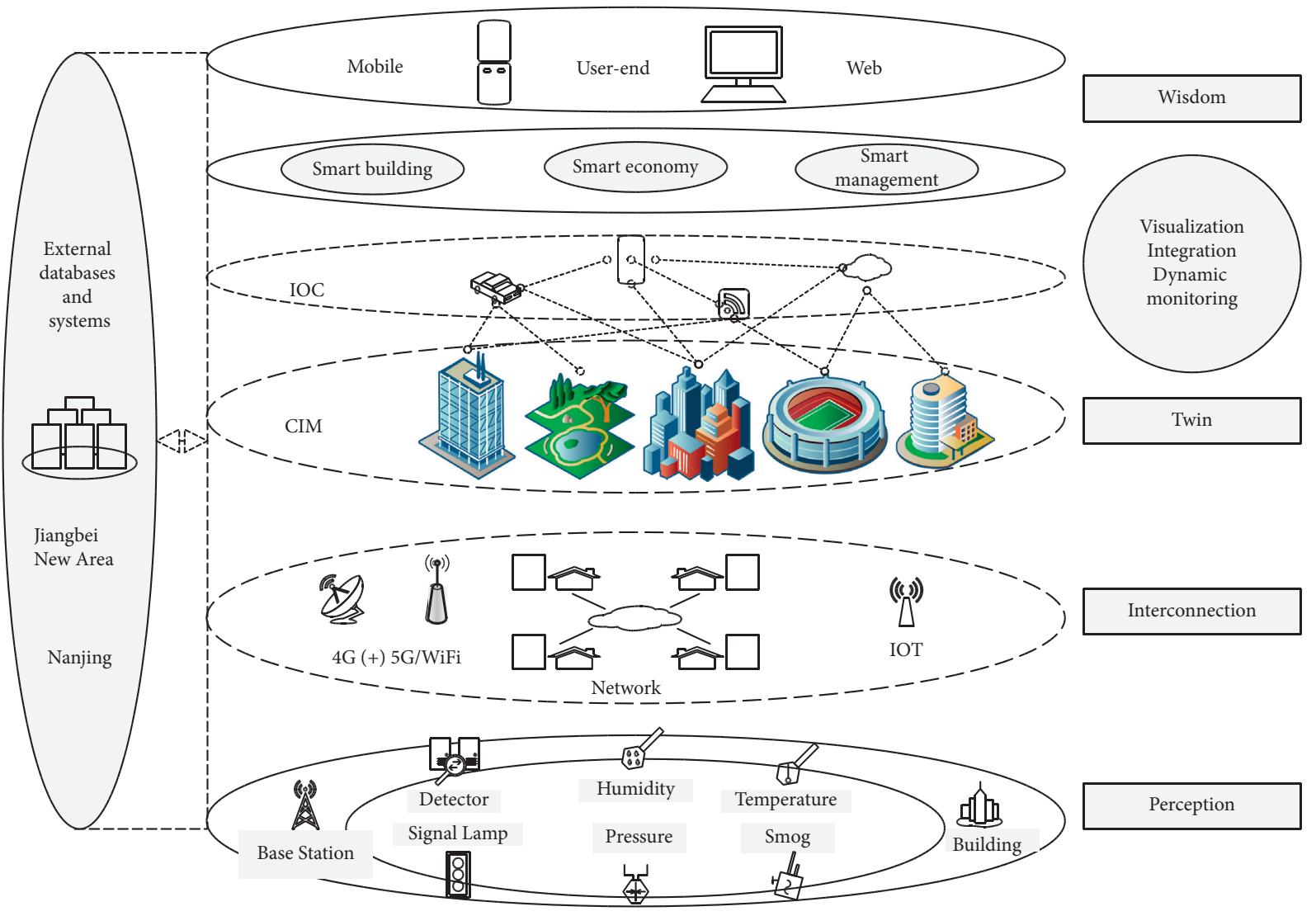

FIgUre 3: The overall structure of the CBD in the Jiangbei New District.

order to achieve effective control of massive sensors and terminal equipment, and ultimately, through the integration of communication networks and the Internet of Things, various front-end data will be aggregated into the urban CIM system in the CBD to support various smart application constructions.

(3) City Information System. As a common support for the construction of smart cities, city information model relies on BIM and GIS, IOT, big data, ICT, business integration, application development, and AI, as shown in Figure 4. And through these rich platform capabilities, organic integration between the three-dimensional urban space model and urban information is achieved. Based on the city information model, it conducts simulation analysis and optimization of various plans for the urban space, public facility layout, land-use change, infrastructure construction, and urban governance services of the CBD so that it breaks through the data barriers in the planning, construction, management, and other stages and transportation, ecology, municipal, and other business areas.

(4) The Third Layer (Smart System Layer). Build an urban intelligent operation center (IOC) and intelligent application system in the CBD to create an intelligent hub that supports dynamic management and control, as shown in Figure 5. The IOC can manage and control the operation status of the
$\mathrm{CBD}$, that is, "visual, controllable, and manageable," and realize business operation coordination in various fields. In addition, the smart service system includes smart management, smart economy, smart life, smart construction, and other service systems to ensure the smart operation of the CBD. In addition, this layer mainly provides services for enterprises, central area companies, nearby residents, and other service objects in two ways: web and mobile.

\subsubsection{Key Projects}

(1) Information Infrastructure. Based on the intelligent positioning and needs of the CBD, the deployment of advanced information infrastructure is the basis for the intelligent development of the CBD. These facilities include high-speed and flexible broadband network engineering, reliable Wi-Fi network engineering, comprehensive coverage of the Internet of Things, a new generation of cloud data centers and information security management platforms, and high-quality and secure network environments.

(2) City Information System (CIM). Implementing the concept of "digital twin city" construction in the CBD and building a city information system (CIM) can realize the visualization of all elements of the dynamic and static urban development. It is convenient for city managers to have clear 


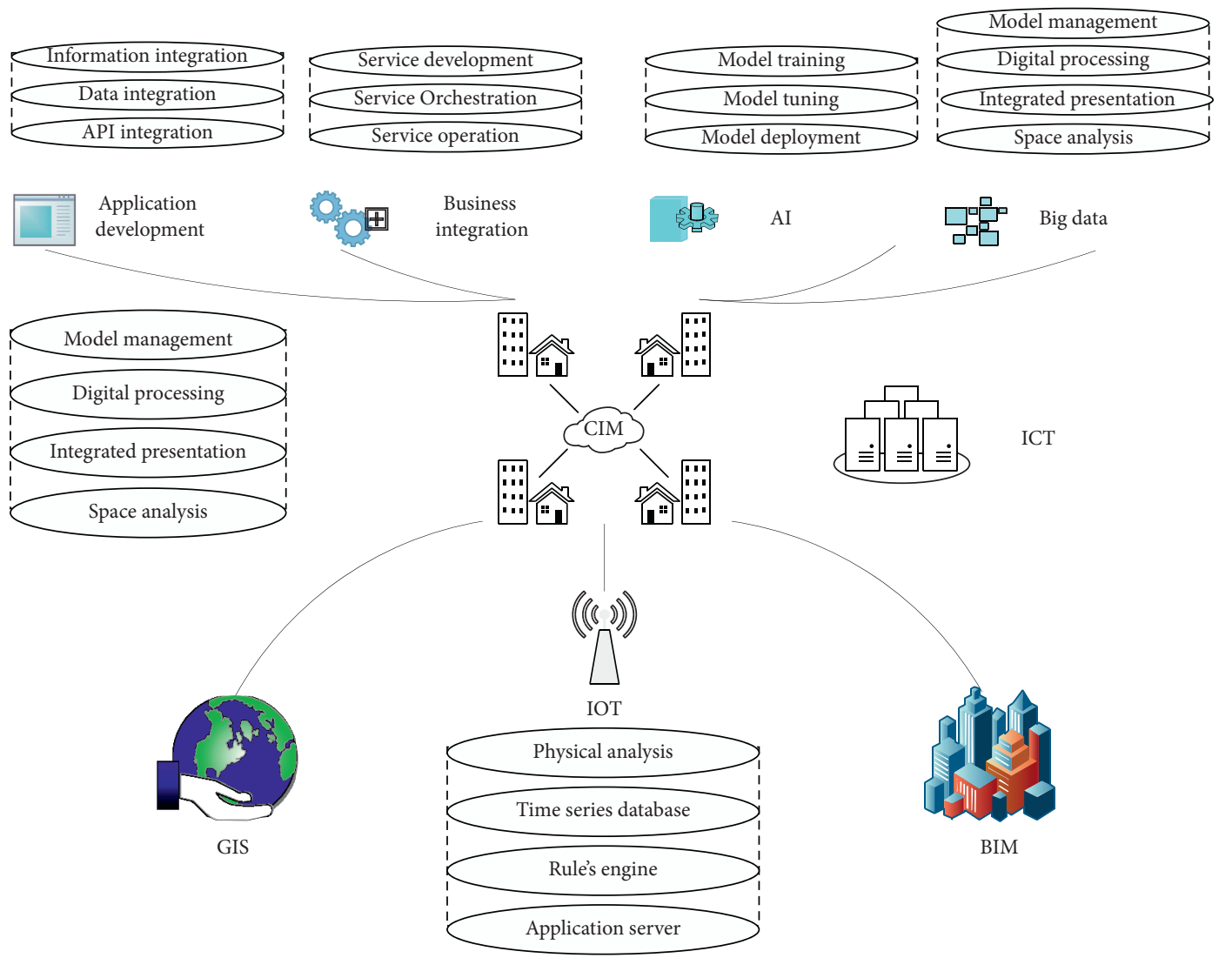

FiguRE 4: The structure of the platform support layer.

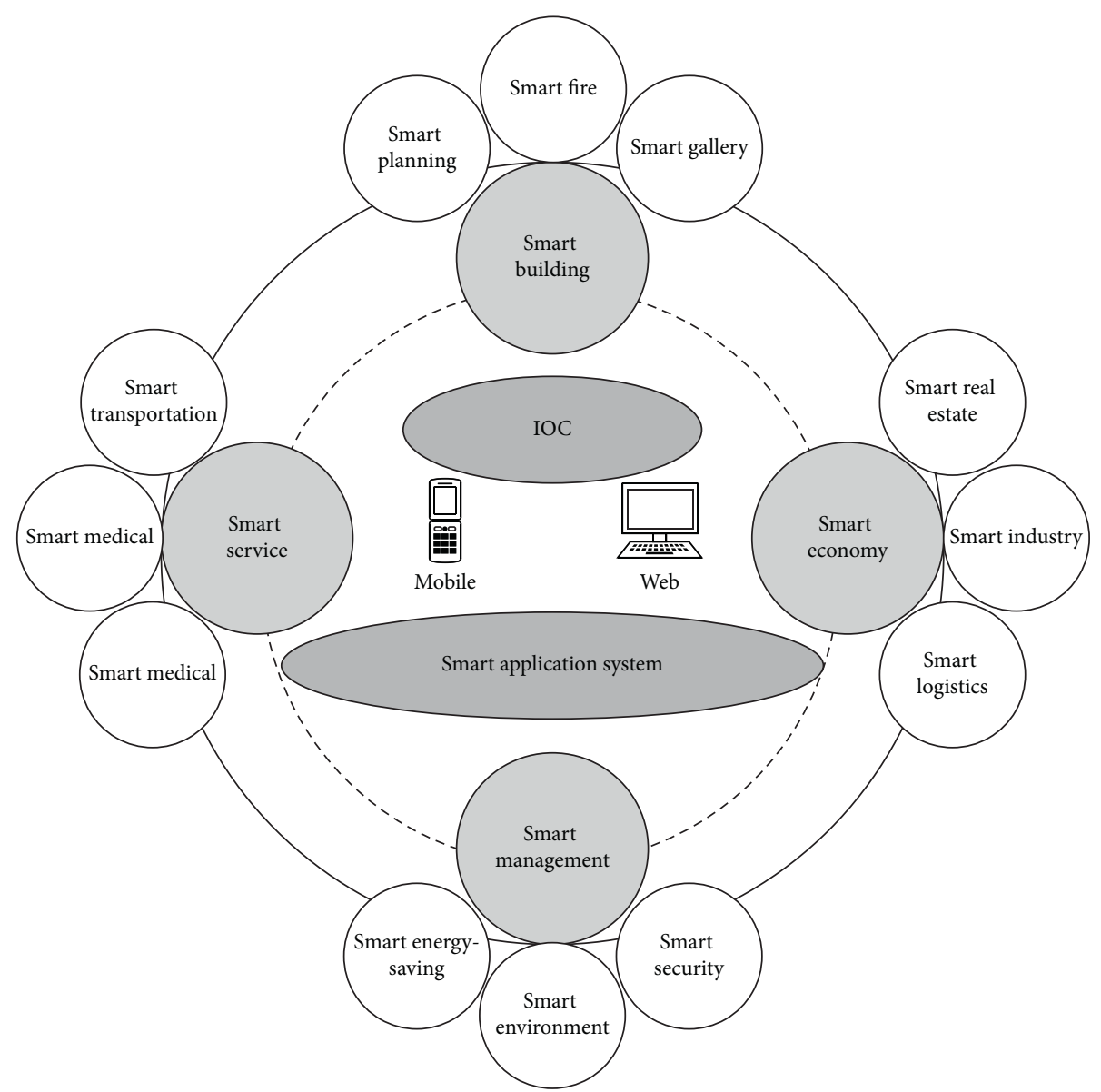

Figure 5: The structure of the smart system layer. 
control over the history, present, and future of urban development from a dynamic perspective, helping decision makers to coordinate the operation and development of the city from a more systematic and comprehensive perspective and make analysis and decision-making. As the basic support platform for smart city construction, the city information system supports the efficient operation of various smart applications. The urban information system mainly includes BIM+GIS capability platform, IOT capability platform, big data support platform, ICT capability open platform, business integration service platform, application development service platform, and AI support platform.

(3) Smart Construction. The smart construction of the CBD relies on the smart construction laboratory to carry out five key projects of "smart buildings, smart ecological landscape, smart transportation, smart municipal administration, smart pipe corridors and pipelines," covering the main components of urban construction in the CBD. Through the use of emerging information technologies such as the Internet of Things and artificial intelligence, the digital construction and intelligent operation and management of urban components are realized, which strongly supports the construction of a digital twin city in the CBD.

(4) Smart Finance. Based on the industrial economy, featuring technology and finance, leveraging human resources, and targeting ecological wisdom and vitality, the CBD relies on new technologies such as artificial intelligence, big data, cloud computing, and blockchain to focus on the financial service needs of new financial companies and target groups and build a new financial service platform. In addition, it also creates a new experience of smart work and life to build an integrated service system for financial technology innovation and incubation, thereby forming an organic unified and interactive development of information technology, financial capital, and industry-city integration in the smart financial district.

(5) Comprehensive Service Platform. Through the construction of the three comprehensive service platforms of enterprise one-stop service platform, neighborhood center service platform, and comprehensive collaborative management platform, it will provide enterprises, communities, and central district companies with efficient, convenient, high-quality, and caring services in an allround way with intelligent means. It has shaped the service-oriented image of the $\mathrm{CBD}$ and built a more humane, more distinctive, and more technological sense of office and residential space.

(6) CBD Operation Management Center. In response to the needs of central area companies for project supervision, comprehensive coordination and scheduling, and auxiliary urban planning, through the construction of a CBD operation center, a smart hub in the CBD will be built to achieve comprehensive monitoring, resource scheduling, and incident handling of the urban construction status of the CBD and decision analysis. The smart operation management center will lead the smart construction and development of the $\mathrm{CBD}$ and serve the entire process of the physical city construction of the CBD. With the gradual construction and improvement of digital twin cities, it will eventually develop into the smart hub of digital twin cities.

(7) Business Model. The continuity, system, coordination, and openness of smart city construction in the CBD require reasonable design of business models. The business model of smart city construction is not equivalent to the general corporate business model, but a city manager-led and integrated business model. In the end, the construction of smart cities must be implemented to solve the problems of "cost-effectiveness," "applicability," and "sustainability" of services. It not only solves the problem of recognition of the "price-performance ratio" of smart city services by urban management units, enterprises and institutions, and urban residents but also more importantly, it solves the problems of how to start construction, how to continue operations, and how to survive reasonably. The construction of smart cities in the CBD should achieve sustainable development in terms of construction and operation, adopt a combination of multiple business models, maximize the use of resources, save funds, and make reasonable investment and long-term benefits.

The smart city construction and operation in the CBD consists of four main modes: self-construction, agent construction, third-party construction, and co-construction. The self-construction model includes two submodels: "self-construction and self-use" and "self-construction and self-operation." The construction model includes two subdivision models, "co-construction and joint operation" and "cooperation." Based on 4 categories and 6 business models, combined with the characteristics of the project construction content, the business model of the Jiangbei New District CBD is shown in Figure 6.

5.1.5. Construction Investment. According to the horizontal analogy method, report analysis method, supplier inquiry method, and expert evaluation method, the investment estimate given by the project is shown in Table 7:

Taking the type of project construction as the statistical dimension, among the total investment of 1.262 billion yuan, the investment in infrastructure projects reached 634 million $\mathrm{RMB}$, accounting for the highest proportion. The investment quotas for other types of construction projects are as follows: smart construction project investment of 256 million yuan, urban CIM system investment of 135 million yuan, CBD operation center (IOC) investment of 78 million yuan, comprehensive service project investment of 78 million yuan, new financial project investment of 57 million yuan, new cultural tourism project investment of 19 million yuan, and future urban laboratory investment of 15 million yuan.

5.2. Result Analysis. In order to evaluate the $\mathrm{CBD}$ of the Jiangbei New District, the survey questionnaires are issued to the people in the Jiangbei New District based on the index evaluation system established in this paper and referring to 


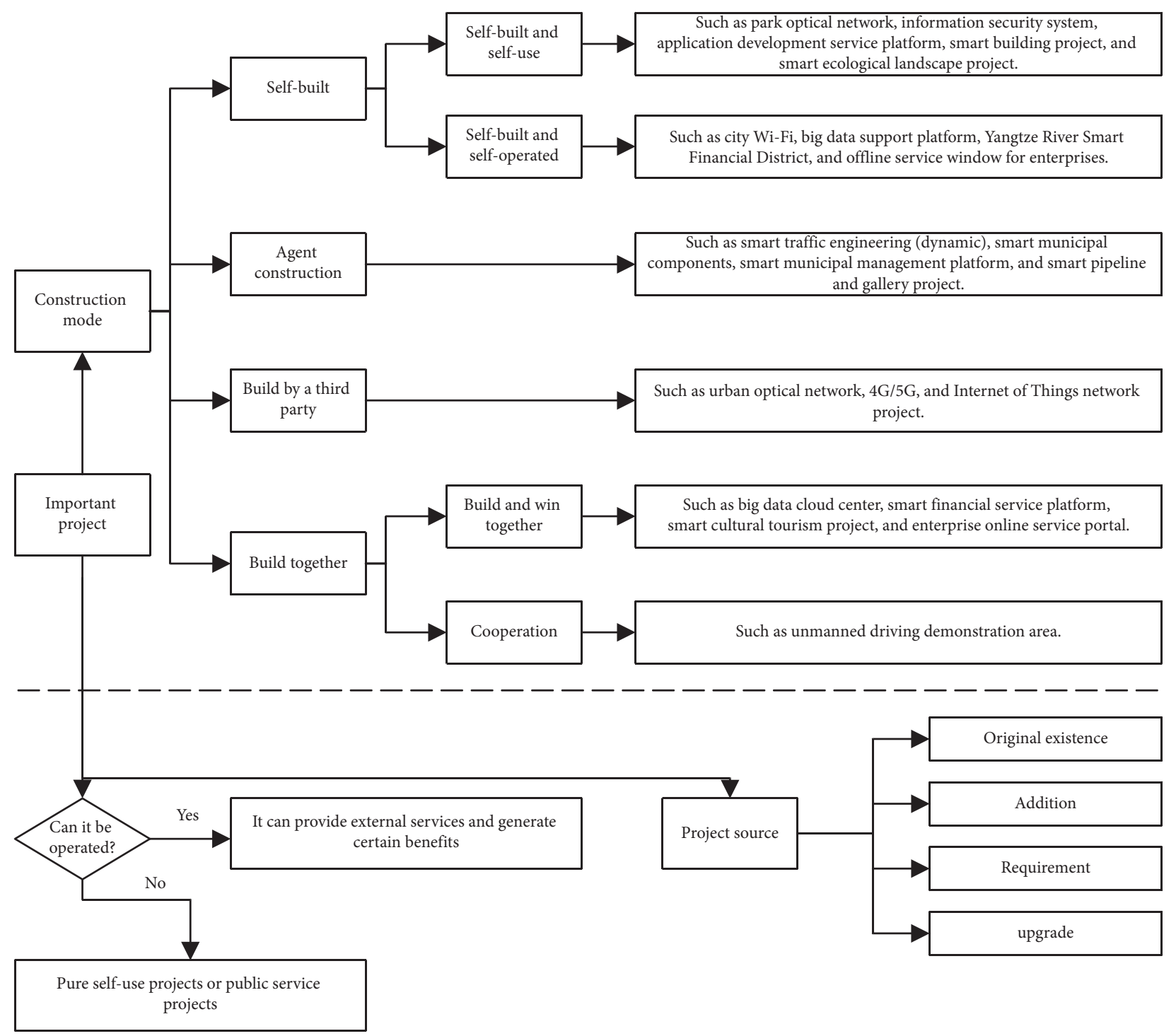

Figure 6: Business model design of the CBD in the Jiangbei New District.

the indicators in the system. Considering that the indicators are targeted for different survey targets, the managers, commercial enterprise users, and ordinary residents are classified according to the content of the index evaluation. According to statistics, a total of 43 valid questionnaires were recalled, including 9 from company managers in the central area of the Jiangbei New District, 14 from commercial enterprise personnel, and 20 from ordinary households. The initial results obtained are as shown in Table 8 .

The evaluation summary results are shown in Table 8 . The comprehensive score of the Jiangbei New District CBD is 92.913, which is in the first level, that is, the smart construction is excellent and needs to be maintained. The construction of the Jiangbei New District's CBD draws on the experience of many excellent CBDs at home and abroad. It can be seen from the evaluation results that even if the Jiangbei New District is still under construction, its advanced planning, design, and construction results have become a leader in the smart CBD. It can be predicted that if the Jiangbei New District is completed according to the plan, it will become an excellent model for the construction of China's CBD in the future.

In addition, the scores and proportions of the third-level indicators are summarized in Table 9. Among them, the contribution rate of "precision governance" is the highest, indicating that the construction of the CBD cannot be separated from smart management. The two indicators of "smart project" and "smart facilities" account for up to $24 \%$. Therefore, in the construction process, professional enterprises should be actively coordinated to complete the construction of digital infrastructure, and the Jiangbei New District should increase capital investment in smart construction projects, improve project financing methods, and promote smart development. 
TABLe 7: Estimates of smart construction projects in the CBD of the Jiangbei New District (2019-2023).

\begin{tabular}{lc}
\hline Construction project & Investment (10,000 RMB) \\
\hline Broadband network & 33,000 \\
IoT network & 1,000 \\
Big data cloud center & 26,000 \\
Information security & 2,400 \\
CIM system & 13,500 \\
Future city lab & 5,300 \\
Smart building & 3,800 \\
Smart ecological landscape & 3,000 \\
Smart transportation & 8,500 \\
Smart municipal & 2.000 \\
Smart pipelines and pipe corridors & 5,300 \\
Financial service platform & 1,200 \\
Smart financial district & 4,500 \\
Smart cultural tourism & 1,900 \\
Enterprise service platform & 2,100 \\
Neighborhood center service platform & 2,100 \\
Smart construction management platform & 3,600 \\
CBD operation center (IOC) & 7,800 \\
\hline
\end{tabular}

TABle 8: Comprehensive rating form for the CBD in the Jiangbei New District.

\begin{tabular}{|c|c|c|c|c|}
\hline Third-level indicator & Fourth-level indicator & Average score & Weight (\%) & Total score \\
\hline \multirow{5}{*}{ Smart project } & Building & 92.78 & 2.60 & 2.412 \\
\hline & Ecological landscape & 90.56 & 2.60 & 2.354 \\
\hline & Municipal administration & 91.67 & 2.60 & 2.383 \\
\hline & Pipeline & 91.67 & 2.60 & 2.383 \\
\hline & Traffic & 90.56 & 2.50 & 2.264 \\
\hline \multirow{3}{*}{ Smart facilities } & Broadband network & 93.26 & 5 & 4.663 \\
\hline & Internet of Things & 92.56 & 3 & 2.777 \\
\hline & Cloud infrastructure & 92.56 & 3.30 & 3.054 \\
\hline \multirow{2}{*}{ Information resource } & Open sharing & 93.37 & 5.10 & 4.762 \\
\hline & Development and utilization & 92.91 & 3 & 2.787 \\
\hline \multirow{2}{*}{ Network security } & Network security mechanism & 93.37 & 3 & 2.801 \\
\hline & System and data security & 93.14 & 3.50 & 3.260 \\
\hline \multirow{3}{*}{ Precision governance } & Digital city management & 92.78 & 7 & 6.494 \\
\hline & City management and intelligent analysis & 92.78 & 6 & 5.567 \\
\hline & Public safety & 91.67 & 1.50 & 1.375 \\
\hline \multirow{3}{*}{ Benefit service } & Traffic service & 93.60 & 1 & 0.936 \\
\hline & Employment services & 93.14 & 1 & 0.931 \\
\hline & City service & 93.84 & 1.20 & 1.126 \\
\hline Enterprise service & One-stop business services & 93.82 & 3.20 & 3.002 \\
\hline \multirow{2}{*}{ Collaborative service } & Coordination office & 92.83 & 1.50 & 1.392 \\
\hline & Construction collaboration & 92.83 & 3.40 & 3.156 \\
\hline \multirow{2}{*}{ Industry service } & New financial industry services & 93.37 & 8.50 & 7.937 \\
\hline & New cultural and tourism industry service & 93.37 & 4.40 & 4.108 \\
\hline \multirow{2}{*}{ Ecologically living } & Smart environmental protection & 93.60 & 1.60 & 1.498 \\
\hline & Green technology & 93.60 & 1.60 & 1.498 \\
\hline Reform and innovation & Mechanism & 92.78 & 4.80 & 4.453 \\
\hline Technological innovation & New technology & 91.67 & 3.20 & 2.933 \\
\hline Smart strategy & Planning and design & 93.89 & 3.20 & 3.004 \\
\hline Citizen experience & Citizen satisfaction & 93.82 & 8.10 & 7.600 \\
\hline
\end{tabular}

\section{Conclusions}

The key to the evaluation of the smart CBD is to establish a systematic and comprehensive evaluation index system that runs through the entire process of the construction of the
CBD. The evaluation of the smart CBD comprehensively considers all beneficiaries, and at the same time, it provides an accurate and objective basis for the CBD builders. Based on domestic and foreign research on the CBD and its own characteristics, an evaluation index system for the smart 
TABLe 9: Percentage of third-level indicators to comprehensive score.

\begin{tabular}{lcc}
\hline Third-level indicator & Total score & Percentage of the comprehensive score \\
\hline Smart project & 11.797 & 0.127 \\
Smart facilities & 10.494 & 0.113 \\
Information resource & 7.549 & 0.081 \\
Network security & 6.061 & 0.065 \\
Precision governance & 13.436 & 0.145 \\
Benefit service & 2.993 & 0.032 \\
Enterprise service & 3.002 & 0.032 \\
Collaborative service & 4.548 & 0.049 \\
Industry service & 12.045 & 0.130 \\
Ecologically living & 2.995 & 0.032 \\
Reform and innovation & 4.453 & 0.048 \\
Technological innovation & 2.933 & 0.032 \\
Smart strategy & 3.004 & 0.032 \\
Citizen experience & 7.600 & 0.082 \\
\hline
\end{tabular}

CBD has been established from six aspects: construction, management, service, innovation, strategy, and users. The first level of the indicator system indicates the overall goal: the evaluation indicator system of the smart CBD. The second level of the system is the six components mentioned earlier. The third level includes 14 key elements, and the fourth level includes 29 specific indicators. This paper uses the Delphi method and analytic hierarchy process (AHP) to determine the weight of each index. At the second level, the weight of "construction" is $38.8 \%$, which is the maximum weight; the weight of "management" is $14.5 \%$, the weight of "service" is $27.4 \%$, and the weight of the remaining indicators is $19.3 \%$. In the construction category, the indexes of "smart project" and "smart facilities" are the two most important factors, so they should be the focus of smart construction in the CBD.

This paper attempts to establish the evaluation index system of the $\mathrm{CBD}$, aiming at providing technical support for the construction of the CBD and smart city for the evaluation of the construction effect, which has guiding significance for the construction of the CBD in China. Based on the recommendations of the expert group, the specific indicators in the experience indicators are classified and empirically evaluated. This study uses the Delphi method and AHP to establish a smart CBD evaluation index system and, through empirical research, to make the results have guiding significance. In addition, this study verified the operability of the evaluation index system through the empirical study of the CBD in the Jiangbei New District. Considering that the indicators are first screened using the Delphi method, the system has limitations in the subjectivity and evaluation criteria of the evaluation index system. The smart CBD does not have a professional evaluation agency. It seeks expert opinions and suggestions and then uses AHP to modify the indicators based on the experts' suggestions. This means that the selection of indicators is based on the subjective judgment of experts to a certain extent, which may lead to underrepresentation. In the evaluation process of the Jiangbei New District, the subjectivity of data collectors will also cause certain deviations in the results. In summary, although this study has limitations, the establishment of an evaluation index system for the smart CBD can lay a good foundation for the future development of the CBD.

\section{Data Availability}

The data used to support the findings of this study are available from the corresponding author upon request.

\section{Conflicts of Interest}

The authors declare that there are no conflicts of interest regarding the publication of this paper.

\section{Acknowledgments}

The authors' special thanks are due to all survey participants and reviewers of the paper and appreciate Postgraduate Research and Practice Innovation Program of Jiangsu Province (KYCX18_0583), Fundamental Research Funds for the Central Universities (2018B610X14), the National Natural Science Foundation of China (72071043), the Natural Science Foundation of Jiangsu Province, China (BK20201280), and the Ministry of Education of Humanities and Social Science Project in China (grant no. 20YJAZH114).

\section{References}

[1] R. G. Hollands, "Will the real smart city please stand up?" City, vol. 12, no. 3, pp. 303-320, 2008.

[2] J. Zacharias and W. Yang, "A short history of the Chinese central business district," Planning Perspectives, vol. 31, no. 4, pp. 611-633, 2016.

[3] E. P. Goodman and J. Powles, "Urbanism under google: lessons from Sidewalk Toronto," Fordham Law Review, vol. 88, no. 2, pp. 457-498, 2019.

[4] G. Anyumba, "Thohoyandou's CBD and the hypothetical accessibility challenges for emergency services," Jàmbá: Journal of Disaster Risk Studies, vol. 11, no. 2, pp. 1996-1421, 2019.

[5] F. Yan, Q. Zhang, and Z. He, "Assessment of fire risk in central business district-taking yujiapu of tianjin city as example," 2015. 
[6] Z. Ayag, F. Samanlioglu, and G. Buyukozkan, “A fuzzy QFD approach to determine supply chain management strategies in the dairy industry," Journal of Intelligent Manufacturing, vol. 24, no. 6, pp. 1111-1122, 2013.

[7] G. Büyüközkan and G. Çifçi, “An integrated QFD framework with multiple formatted and incomplete preferences: a sustainable supply chain application," Applied Soft Computing, vol. 13, no. 9, pp. 3931-3941, 2013.

[8] S. Zhang, "Demands analysis for the CBD building projects based on quality function deployment," 2015.

[9] R. E. Rubin, "A smarter planet: the next leadership agenda," IBM Business Leadership Forum in Istanbul, Turkey, November, vol. 12, 2008.

[10] S. Graham, "Bridging urban digital divides? Urban polarisation and information and communications technologies (ICTs)," Urban Studies, vol. 39, no. 1, pp. 33-56, 2002.

[11] C. G. Harrison, B. Eckman, R. Hamilton et al., "Foundations for smarter cities," IBM Journal of Research and Development, vol. 54, no. 4, pp. 350-365, 2010.

[12] C. Hafedh, N. Taewoo, W. Shawn, and J. Ramon G, M. SehlN. Karine et al., "Understanding Smart Cities: An Integrative Framework," in Proceedings of the 45th Hawaii International Conference on System Sciences, Washington, DC, USA, 2012.

[13] L. Nautiyal, P. Malik, and A. Agarwal, "Cybersecurity system: an essential pillar of smart cities," in Smart Cities. Computer Communications and Networks, Z. Mahmood, Ed., Springer, Berlin, Germany, 2018.

[14] S. Zygiaris, "Smart city reference model: assisting planners to conceptualize the building of smart city innovation ecosystems," Journal of The Knowledge Economy, vol. 4, no. 2, pp. 217-231, 2013.

[15] K. Bakker and M. Ritts, "Smart Earth: a meta-review and implications for environmental governance," Global Environmental Change, vol. 52, pp. 201-211, 2018.

[16] K. J. Fietkiewicz and W. G. Stock, "How "smart" are Japanese cities? An empirical investigation of infrastructures and governmental programs in Tokyo, Yokohama, Osaka, and Kyoto," in Proceedings of the 48th Hawaii International Conference on System Sciences, Kauai, HI, USA, January 2015.

[17] S. L. Hoe, "Defining a smart nation: the case of Singapore," Journal of Information, Communication and Ethics in Society, vol. 14, no. 4, pp. 323-333, 2016.

[18] F. Granelli, T. F. Rahman, C. Sacchi et al., "The role of small cell technology in future Smart City applications," European Transactions on Telecommunications, vol. 25, no. 1, pp. 11-20, 2014.

[19] P. Lombardi, S. Giordano, and H. Farouh, "Modelling the smart city performance," Innovation: The European Journal of Social Science Research, vol. 25, no. 2, pp. 137-149, 2012.

[20] T. Nam and T. A. Pardo, "Conceptualizing smart city with dimensions of technology, people, and institutions," 2011.

[21] T. Bakıc1, E. Almirall, and J. Wareham, "A smart city initiative: the case of barcelona," Journal of the Knowledge Economy, vol. 4, no. 2, pp. 135-148, 2013.

[22] D. Koh, A Study on the Smart City Construction and the Evaluation System-A Case Study of Shanghai, Shanghai Jiao Tong University, Shanghai, China, 2014.

[23] Y. Qu, Study on the Evaluation System of the Construction Level of Smart City on China, Dalian University of Technology, Dalian, China, 2017.

[24] G. Li, Y. Wang, J. Luo et al., "Evaluation on construction level of smart city: an empirical study from twenty Chinese cities," Sustainability, vol. 10, no. 9, 2018.
[25] S. Paroutis, M. Bennett, and L. Heracleous, "A strategic view on smart city technology: the case of IBM Smarter Cities during a recession," Technological Forecasting and Social Change, vol. 89, pp. 262-272, 2014.

[26] P. Ma, G. Ye, X. Peng, J. Liu, J. Qi, and S. Jia, "Development of an index system for evaluation of ecological carrying capacity of marine ecosystems," Ocean \& Coastal Management, vol. 144, pp. 23-30, 2017.

[27] Q. Cheng, B. Su, and J. Tan, "Developing an evaluation index system for low-carbon tourist attractions in China-a case study examining the Xixi wetland," Tourism Management, vol. 36, pp. 314-320, 2013.

[28] H. Feng, "Research on evaluation system of smart city construction based on analytic hierarchy process," in Proceedings of the 7th International Conference on Education, Management, Information and Computer Science (ICEMC 2017), Shenyang, China, June 2017.

[29] K. B. Ko, Y. H. Kang, and K. S. Hwang, "A study on the establishment of evaluation indicators for smart traffic safety city in Jeju island," Korea Association of Local Administration, vol. 17, no. 1, pp. 109-133, 2020.

[30] O. Halpern, J. Lecavalier, N. Calvillo, and W. Pietsch, "Testbed urbanism," Public Culture, vol. 25, no. 70, pp. 272-306, 2013.

[31] R. Lobo, "South Korea's High Tech City: Songdo. Business Destinations," 2013.

[32] N. T. Rugkhapan and M. J. Murray, "Songdo IBD (International Business District): experimental prototype for the city of tomorrow?" International Planning Studies, vol. 24, no. 3-4, pp. 272-292, 2019.

[33] S. T. Shwayri, "A model Korean ubiquitous eco-city? The politics of making Songdo," Journal of Urban Technology, vol. 20, no. 1, pp. 39-55, 2013.

[34] Y. Sun, "Development and characteristics of CBD under the philosophy of health," Procedia Engineering, vol. 21, pp. 258-266, 2011.

[35] A. Vanolo, "Smartmentality: the smart city as disciplinary strategy," Urban Studies, vol. 51, no. 5, pp. 883-898, 2014.

[36] S. R. Henderson, "City centre retail development in England: land assembly and business experiences of area change processes," Geoforum, vol. 42, no. 5, pp. 592-602, 2011.

[37] E.-S. Säynäjoki, V. Inkeri, J. Heinonen, and S. Junnila, "How central business district developments facilitate environmental sustainability-a multiple case study in Finland," Cities, vol. 41, no. 1, pp. 101-113, 2014.

[38] Evaluation Indicators for New-type Smart Cities GB/T 333562016, 2016, http://openstd.samr.gov.cn.

[39] D. M. Sun and P. P. Li, "Construction and case study of evaluation index system on the information security of smart city," 2017.

[40] AQSIQ and Standardization Administration of China, GB/T 33356-2016. Evaluation Indicators for New-type Smart cities, China Standard Press, Beijing, China, 2016.

[41] L. Shen, Z. Huang, S. W. Wong, S. Liao, and Y. Lou, "A holistic evaluation of smart city performance in the context of China," Journal of Cleaner Production, vol. 200, no. 11, pp. 667-679, 2018. 